\title{
ABSTRACTS
}

\section{SOME REMARKS ON METHODOLOGY FOR THE STUDY OF THINKING}

\section{-Experimental Studies of Children's Concept-Formation-}

\author{
by \\ Hiroko Kushida \\ Ritsumeikan University
}

Recently, several research groups studying of thinking have done very useful achivements; the study of (conservation) concept by Piaget, J. and his followers, the representational mediation process theory by Kendler, H. H. and others.

But some experiments of thinking have many weak points from the standpoint of methodology.

Some weak points of Piaget's studies are as follows ;

1) (Groupement) is not ultimate principle of logical thinking. It is only a part of logical thinking.

2) (Equilibration)concept has not substantiality

3) His studies did not make clear the influence of verbal behavior and conditions of teaching. As for Kendler and others ;

1) They recognized thinking only as common responses to external stimuli, but could not recognized it as a process of congnition.

Purpose :

The purpose of this study is to examine these weak points in study of thinking. The Following conditions are used in these experiments on concept formation :

1) selection of suitable materials,

2) conditions of teaching,

3) verbal behavior:

Procedure :

The subjects are 111 preschool childrens, 5-6 years old, IQ above 90 (Tanaka-Binet test). The experimental material consists of 84 wooden blocks varying in color, shape, height and size. There are six different colors : red, blue, yellow, green, white and purple ; five different shapes : circles, squares, triangles, lozenges and horseshoes ; two heights : tall blocks and flat blocks; and two size of top (or bottom) area : large and small blocks. All blocks were named after one of following nonsense syllables. Regardless of color and shape, EKA is all large tall figures, TAYO is all small tall ones. NERI is all large flat ones and KENI is the small flat ones. Subjects had to form such four concepts as EKA, TAYO, NERI and KENI through classifying 12 mixed blocks.

The main results were as follows;

1) As the materials for effective concept-formation, E had to select materials by which Ss become clearly aware of their vague question about the concept of form.

2) "Reproductive-synthetic method", which I devised, was found to be effective espcially for Ss who had some knowledge about concepts in question.

3) "Synthetic method through analysis"' was considered to be one of the most reliable methods of concept formation and development, as $\mathrm{E}$ could recognize Ss' different developmental stages of conceptual thinking. 